\title{
PROJECT NETWORK MANAGEMENT: RISKS AND CONTRIBUTORS FROM THE VIEWPOINT OF CONTRACTORS AND SUB-CONTRACTORS
}

\author{
Bon Gang HWANG ${ }^{\mathrm{a}}$, Han Boey NG \\ ${ }^{a}$ Department of Building, National University of Singapore, Singapore, Singapore \\ ${ }^{b}$ Quantity Surveyor, Shimizu Corporation, Singapore, Singapore
}

Received 24 October 2012; accepted 02 November 2013

\begin{abstract}
Over the years, the network of construction project participants has expanded immensely. Clients have more stringent requirements due to increasing project complexity, difficulties with interaction and coordination, and uncertainties among various stakeholders. Emergent issues can bring many uncertain risks to the project execution process and yet the body of knowledge in this area, as applied to the Singapore construction environment, is insufficient. Therefore, the main objective of this study is to identify critical network risks extant in the industry in order to attain a better understanding of the attitudes of stakeholders towards network risk management. Thirtythree construction companies participated in a survey developed for this study and the analysis of the responses identified ten top critical network risks and the stakeholders who most contribute to these risks. The findings from this study will help the industry to promote a healthy working relationship among stakeholders, and will further facilitate collaboration within the project network.
\end{abstract}

Keywords: network management, risk management, communication, stakeholder.

JEL Classification: L74, O22, O53.

\section{Introduction}

The construction industry project environment is constituted of stakeholders from different disciplinary fields, and each of them is driven to accomplish their own works. Nonetheless, there is a high level of interdependency among these stakeholders as they are closely connected with one another in the project network (Shirazi et al. 1996). Cleland (1999) argued that in order to ensure the successful completion of project deliverables, it is crucial to adopt effective and efficient relationship management processes for the parties in the project network. Implementing the processes for managing relationship among project

Corresponding author Bon Gang Hwang

E-mail: bdghbg@nus.edu.sg 
participants can make it possible to attain project objectives and to address the expectations of stakeholders throughout the project lifecycle.

According to Schwegler et al. (2001), coordination of all the parties in the project network is a challenging task, and if the constant changes and uncertainties in the network are not managed properly, risk is an inevitable result. Here, project network risk can be defined as an uncertain event or condition that results from work linkages, and it has an impact that contradicts the expectations of stakeholders (Lowe, Leiringer 2006). Due to the phenomenal increase in the number of stakeholders from multiple disciplinary parties in the construction environment, the complexity in the project network has amplified and the number of possible uncertainties has increased. One of the prominent risks resulting from a complex network is the difference in interest and opinions that each stakeholder holds, which may contribute to disputes among them (Ward, Chapman 2008). Also, poor communication among various stakeholders can be another possible network risk as it may result in various problems such as poor project definition, inadequate pre-project planning, design errors, omissions, or modifications to the drawings leading to ineffective design, or inadequate project change management, ultimately reducing the probability of project success (Hwang, Low 2012).

While there have been a great number of studies on project risk management, few research studies have dealt with the specific risks residing in the complex project network structure in which multiple stakeholders are required to work together. Considering that the risks can adversely affect the work-linkages in the project network, hinder the stakeholders from achieving pre-set objectives of their projects, and eventually result in project failure, it is required to identify ways of making the project network sustainable than can overcome potential challenges. As a result, this study aims: (1) to explore the attitudes and understanding of project network management; (2) to identify critical risks that affect the construction project network; and (3) to determine stakeholders who most contribute to the critical risks. By gaining a thorough understanding of relationships among the various stakeholders in the project network as well as the critical risks related to the network structure, more effective project risk management can be carried out, ultimately increasing the probability of project success.

\section{Background}

\subsection{Construction project network}

The construction industry is constituted of a high number of different project participants who have distributed responsibilities. The result is a complex network organization in the project environment. In fact, the overall complexity is significant due to the multi-cultural, multi-social, multi-location, multi-disciplinary, and multi-organizational nature of the project participants (Schwegler et al. 2001; Nayak, Taylor 2009; Chinowsky et al. 2010; Wong et al. 2010; Park et al. 2011). Contractors in the construction industry typically subcontract significant portions of the project to special trade contractors (Eccles 1981). Subcontracting increases the number of players in the construction network and the coordination of all the 
specialized and differentiated tasks required to complete a construction project leads to the need for more intense interaction between the players (Shirazi et al. 1996).

According to Mitchell et al. (1997), a project stakeholder is a person or a group of people who has a vested interest in the overall success of a project and the environment within which the project functions. Expectations of stakeholders are generally a combination of functionality, aesthetics, culture, technology, cost and quality. The main parties who ensure that such requirements can be achieved include the design consultant, contractor, subcontractor, project manager, supplier, and sometimes, coordination consultancy. Due to the different needs of stakeholders, which often are in conflict with one another, it is almost impossible to meet the expectations of all the stakeholders in a project network (McManus 2002). As a result, stakeholders can be considered one of the major network risks and it is thus crucial to evaluate which expectations and needs of stakeholders have to be prioritized and fulfilled.

\subsection{Management of project network}

The level of information that is transferred among different stakeholders is closely connected with the level of information dependencies among these project players. According to Pekericli et al. (2003), there are several aspects that must be considered to ensure the reliability of transferred information and to effectively model the information dependencies between these agents. These aspects include sensitivity, timing, and frequency of communication. Sensitivity is the most critical characteristic as it determines the level of information detail that a party needs in order to perform well in the construction process. It also reflects how information transfer can directly or indirectly affect others. The timeliness of information delivery is also crucial as it is an indicator of reliability. Information that is not delivered on-time may be outdated or may change, thus its reliability may be affected negatively. Frequency of communication is an indicator of the strength of connection amongst the project players. Frequent communication helps ensure that critical content is conveyed in time across the whole construction network. It is essential for management to correctly ascertain the requirements for an effective communication infrastructure to ensure that these three characteristics are fulfilled.

Given the fact that omissions and information inaccuracies are among the major causes of problems in construction (Howell, Ballard 1997), it follows that the success of a construction project hangs on well-managed, precision conveyance of information within the network. As suggested by Thomas (2000), greater use of information technology results in better project performance. Furthermore, the selection of formal and appropriate communication tools and systems to address expectations of stakeholders is crucial. Kazi et al. (2009) suggested that there are eight criteria, namely Cost, Reliability, Security, Scalability, Mobility, Ease of Installation and Management, Application Services and Use, and Overall Performance for assessing the performance of communication tools, and their suitability for the construction organization.

In addition, the partnering process establishes a positive working relationship among stakeholders in the project network through a mutually-developed, formal strategy of com- 
mitment and communication. As defined by the Construction Forum (1995), partnering is a management approach that is effective in achieving specific objectives by two or more organizations. The fundamental principal of this approach is to encourage stakeholders in a project network to work together in an environment of trust and openness to ensure the feasibility of the construction project. It is based upon mutual objectives and an agreed method of resolving disputes while supporting continuous improvement (Bennet, Jayes 1995).

Social network mapping is another useful tool to effectively visualize the power and influence patterns of stakeholders in a construction project network (Bourne, Walker 2005; Park et al. 2011). It works by arranging stakeholders in a hierarchy and analyzing each of the stakeholder's position as an influencer and shaper of ideas and opinions. Communities of Practice (COPs) also help people in a network to collaborate with one another to solve problems as well as to share their knowledge (Love 2009). It is a powerful influencing mechanism due to the intrinsic trust that is built within them. Nonetheless, such a technique is often scarcely visible in the stakeholder network where parallel concerns are shared and interacting on an ongoing basis is essential (Wenger 1998). In a COP, stakeholders are brought together as they work on common activities and as they need mutual engagement in these activities to achieve project success.

SHAMPU, which stands for Sharpness, Harness, and Managing Project Uncertainty, is a generic project risk management process framework which provides a useful structure in identifying and managing stakeholder's uncertainty in a coherent and a comprehensive manner (Chapman, Ward 2003). The most critical management uncertainty issues are usually caused by the complex relationships and differing concerns of key stakeholders. Therefore, it is essential to maintain a comprehensive list of all project participants who may prove central to the project. It is also useful to define and classify relevant stakeholders in the project network who have a direct impact or interest in the project (Mitchell et al. 1997).

\subsection{Common project network risks in the construction industry}

\subsubsection{Different interests and opinions}

Tasks in projects are typically divided according to each field's functional discipline and consequently each operates quite independently. This results in actors developing their own objectives, goals and value systems without consideration for the impact on others or the effects on project performance (Love et al. 1999). These actors can influence the project's shape and progress and inadequate management of the concerns and interest of each stakeholder can result in conflicts and controversies during the implementation of the construction project (Ward, Chapman 2008).

\subsubsection{Lack of trust and commitment}

Most of the time, the role of the individual actor is defined in the contracts, but instead of utilizing these agreements to build alignment for example, contract forms seem to be used more often as instruments to assign liability and attach blame as negative events occur 
(Cox, Thompson 1997). This can result in parties losing trust among one another. Without sufficient mutual trust, it is difficult for stakeholders to operate in an open environment, resulting in lack of commitment (Girmscheid, Brockmann 2010).

\subsubsection{Different organization styles}

Network risk can also occur internally. As suggested by Horii et al. (2005), different organization styles coupled with different micro level employee behavior patterns can affect productivity, which can in turn pose a threat to the internal network. The best employee behavioral style is the one that matches the organizational style implemented.

\subsubsection{Different cultural norms}

English (2002) suggested that foreign companies that are established in Singapore encounter communication issues due to differences in language and culture. The construction industry employs a great number of players and it is inevitable that people from different cultures will work together at times. In a survey of construction professionals with international project experience, it was discovered that cultural difference among professionals contributed to most disputes. In addition, several researchers proved that the differences in cultural contexts still exist in collaborations, resulting in boundaries within projects teams that can prohibit knowledge transfer (Chen et al. 2009; Levina, Vaast 2008; Ozorhon et al. 2008; Di Marco et al. 2010).

\subsubsection{Different work practices}

Insufficient skills to handle interactions with stakeholders from foreign countries in the construction network can lead to increased risks in completing projects on schedule, under budget and within quality specifications. It is important to understand how to manage working with foreign partners and their work practices in order to avoid risks such as unanticipated cultural conflicts, contract misunderstandings, technology interoperability problems, misaligned work practices and communication issues (Nayak, Taylor 2009).

\subsubsection{Occurrence of disputes}

Construction network risk mainly involves the stakeholders and is a major source of uncertainty in a construction project. When stakeholders have a negative attitude towards the construction project, its implementation can be severely obstructed, which will in turn lead to other risks such as cost and schedule overruns. When the interests and concerns of stakeholders in the network are not well-taken care of, disputes are inevitable (McIntosh, McCable 2003).

\subsubsection{Dynamic changes encountered in the project network}

Stakeholders can influence a project at different stages of the project life cycle and the amount of power that each stakeholder possesses differs as well. Changes in relationships between different stakeholders at different stages of the construction project can be difficult to track and manage. 


\subsubsection{Extensive subcontracting leading to increased network complexity}

The construction industry is constantly challenged by risk because of the complexity, dynamic characteristics and inherent uncertainties in the construction process (Al-Bahar, Crandall 1990; Flanagan, Norman 1993; Hwang et al. 2014; Zhao et al. 2013). For instance, hiring sub-contractors to undertake work can pose a risk because the main contractor might lose control over sub-contractor activities (Bova 1995). When changes occur, several parties are often affected and there is a need for them to interact with one another in order to arrive at a compromised decision. However, a wide project network as well as schedule constraints make such alignment difficult. On the other hand, modifications sometimes provide significant opportunities for joint learning, which can create a breeding ground for a positive network effect (Klemetti 2006).

\subsubsection{Lack of risk management knowledge}

When managers lack formal risk management knowledge, project risks cannot be managed systematically. Without this knowledge, procedures to identify possible risks and prevent them from occurring are not in place. Existing risk management methods in today's construction industry might not be flexible enough to fit the dynamics of a construction project, however. It is important for managers to continuously learn the latest risk management techniques available in order to meet the ever-changing needs of the construction industry (Klemetti 2006).

\subsubsection{Lack of experience}

The talent and education level of stakeholders in the network varies significantly. This can directly affect the quality and productivity of the work. The amount of time that is spent on identifying risks and preparing for possible problems that might occur may not be wellunderstood by people who have just entered the industry (Klemetti 2006).

\subsubsection{Incomplete Dissemination of Information}

When needed information is not disseminated to stakeholders in the project network, misunderstandings can lead to a delay in project completion. Causes for incomplete information can range from failure to turn up for the right meeting to using an inefficient communication technology (Klemetti 2006).

\subsubsection{Subcontractor's subcontracting}

Subcontracting is another construction project risk as one can never be completely certain who will actually perform the work. This situation is exacerbated if the subcontractor subcontracts the work out without informing the main contractor. Important information may not be delivered to the subcontractor's subcontractor as they are not officially part of the project network (Klemetti 2006). 


\section{Methodology}

The literature review provided a foundational understanding on the current practice of network management, the potential network risks that are present, and the project network risk management techniques that are available in the construction industry. It served as a solid basis for the development of a survey questionnaire and the interpretation of the results. The main purpose of the survey was to investigate the current status of network management and to identify the network risks most widely faced by the Singapore construction industry. The first section of the questionnaire recorded the profile for each of the respondents participating in the survey. The second section posed questions aiming to identify which stakeholder in the project network has the highest influence on project success and which stakeholder most contributes to uncertainty in a project. Also, project communication effectiveness within the network was included in the questionnaire because a wide network requires a stable and appropriate communication system in order to perform well. Causes of communication difficulty were listed in the questionnaire for respondents to rank. The next section of the survey included a set of questions capturing current network management practices used within the respondents' companies while the last section was focused on identifying a set of critical risk factors affecting the project network.

The survey questionnaire was sent out to construction companies registered under the Building Construction Authority (BCA) registry. The survey targeted contractors and subcontractors as it is common practice for primary contractors to outsource work functions to sub-contractors specialists. This is a major cause of the expanding project network and contributes to its complexity and concurrent network risks. While there are more than contractors and subcontractors that involve a project, including owners, designers, consultants, etc, this study focused only on the perspectives of contractors and subcontractors to provide a comprehensive and profound analysis on how these two parties contribute to the project network and what types of network risks are perceived most by the parties.

The data collection effort produced 33 completed questionnaires from 33 different companies. The survey asked each participating company to complete the questionnaire by assigning a representative with sufficient knowledge and experience in the operations and work processes of the company. Of the companies who participated in the survey, $82 \%$ were contractors (26) and the rest were subcontractors (7). All the contractors were general (main) contractors in charge of the entire construction process of projects, while the business scope of the subcontractors involved excavation, structure, mechanical and electrical works. Most of the surveyed companies (19) had more than 150 employees (150-250) twelve companies employed from 251 to 350, five companies employed from 351 to 500 and one employed greater than 500 people. A total of $65 \%$ of the respondents (22) had at least 15 years of experience in the construction industry. 


\section{Data analysis and discussions}

\subsection{Stakeholders in the construction project network}

Stakeholders are key to the successful management of a complex project network. Consequently, it is important to understand their involvement in order to create a strong foundation for the data analysis, covered in the later sections. Table 1 illustrates the frequency of communication among stakeholders and pinpoints the ones who are most often contacted by other project participants in construction projects. For this study, contractors indicate general contractors who make contracts directly with clients and who are in charge of the entire construction of projects, while subcontractors indicate ones who work for general contractors under contracts made with general contractors. Furthermore, project managers are the ones hired by clients or general contractors for project management or construction management, respectively.

Each respondent was given a maximum of three choices to select the parties with whom they are required to work closely. The results show that the designer, subcontractor and project manager are the most frequent parties with whom respondents need to constantly communicate in the project network to ensure the smooth delivery of the end product. It is important to note that the respondent group was limited to contractors and subcontractors, which constitutes part of the reason for this results pattern.

The analysis revealed active communication with designers. This may be because designers often emphasize aestheticism while contractors pay more attention to the constructability of the project. This leads to the need for both parties to coordinate and compromise with each other frequently to produce a final product which satisfies the concerns of both, and most importantly, the client. Also, as argued by Eccles (1981), because extensive subcontracting is now a common practice, frequent contact with subcontractors is common. The project manager is usually the representative of the client, so contractors look to them to discuss matters on construction and the expectations of the client. The working relationships among these stakeholders form an inter-connected, complex network. Table 1 provides the degree of influence that each stakeholder has on the success of a project. It shows that respondents reported that designers and contractors play an important role in delivering the project. This result might be expected because designers and contractors are the two main bodies in charge of the final outcome of the project.

Critical activities that are not adequately accomplished impact on the schedule, budget and quality requirements expected by the client. As shown in Table 1, the respondents reported that designers might be the one of the stakeholders responsible for the most critical activities. Although the result was based on the perception of only the contractors and subcontractors surveyed for this study, it can be seen that without an accurate, comprehensive design, the parties in the network may not be assured of the exact scope of their work. Furthermore, late changes may cause rework which contributes to wastage of resources. The construction process is the primary component of the construction project and requires the most money and longest duration, compared to the rest of the processes. During the construction process, numerous activities are involved and any delay in critical activities affect the entire construction schedule. As a result, it is not surprising that contractors are placed as the second most liable stakeholder in Table 1. 
Table 1. Analysis results - stakeholders

\begin{tabular}{|c|c|c|}
\hline Topic & Stakeholder & No \\
\hline \multirow{5}{*}{$\begin{array}{l}\text { Frequency of communication } \\
\text { among stakeholders }\end{array}$} & Designer & 27 \\
\hline & Contractor & 14 \\
\hline & Subcontractor & 21 \\
\hline & Supplier & 18 \\
\hline & Project Manager & 19 \\
\hline \multirow{5}{*}{$\begin{array}{l}\text { Degree of stakeholders' } \\
\text { influence on project success }\end{array}$} & Designer & 11 \\
\hline & Contractor & 11 \\
\hline & Subcontractor & 4 \\
\hline & Supplier & 0 \\
\hline & Project Manager & 7 \\
\hline \multirow{5}{*}{$\begin{array}{l}\text { Liable stakeholders for most } \\
\text { critical activities }\end{array}$} & Designer & 11 \\
\hline & Contractor & 9 \\
\hline & Subcontractor & 8 \\
\hline & Supplier & 0 \\
\hline & Project Manager & 5 \\
\hline \multirow[t]{7}{*}{ Sources of uncertainty } & Designer & 26 \\
\hline & Contractor & 21 \\
\hline & Subcontractor & 22 \\
\hline & Supplier & 0 \\
\hline & Project Manager & 17 \\
\hline & Developer & 1 \\
\hline & Local Authorities & 1 \\
\hline
\end{tabular}

Uncertainties contributed by stakeholders cause risks throughout the project network. It is important to identify the stakeholders who contribute the most uncertainty to a construction project. As presented in Table 1, designers were reported to be the top source that contributes to uncertainty, followed by subcontractors. Considering that designers determine the construction design and any changes to the design can lead to changes that affect contractors, this result would be expected.

\subsection{Construction project network risks}

After the literature review, 20 project networks risks were identified and included in the survey questionnaire. The details of the risks were discussed previously in the Background section and are summarized below in Table 2. After collating the survey responses, the network risks were ranked according to the frequency that respondents chose them and the result is also presented in Table 2. Further analyses were performed on the top ten risks, as presented in Table 3, to identify their likelihood and impact of occurrence on a scale from 1 to 10, where 1 represents the risks that are least likely occur and 10 indicates the most likely occurrence. This finding can be used to alert stakeholders of the risks which they might encounter most often. With this knowledge, they can be better prepared for when risk does occur. 
Table 2. Analysis results - network risks

\begin{tabular}{lcc}
\hline \multicolumn{1}{c}{ Network risks } & No & $\%$ \\
\hline Different cultural norms & 19 & $58 \%$ \\
\hline Different institutional norms & 8 & $24 \%$ \\
\hline Different organizational style & 11 & $33 \%$ \\
\hline Different work practices & 22 & $67 \%$ \\
\hline Employees' behavioural style & 13 & $39 \%$ \\
\hline Misinterpretation of contract details & 11 & $33 \%$ \\
\hline Incompatible work technology & 15 & $45 \%$ \\
\hline $\begin{array}{l}\text { Incomplete dissemination of } \\
\text { information }\end{array}$ & 12 & $36 \%$ \\
\hline Inaccurate information delivery & 17 & $52 \%$ \\
\hline Lack of coordination and & 18 & $55 \%$ \\
communication & & \\
\hline Lack of trust and commitment & 28 & $85 \%$ \\
\hline Lack of risk management & 16 & $48 \%$ \\
knowledge & & \\
\hline Lack of risk management discipline & 13 & $39 \%$ \\
\hline Lack of experience & 12 & $36 \%$ \\
\hline Extensive subcontracting & 22 & $67 \%$ \\
\hline Subcontractor's subcontracting & 19 & $58 \%$ \\
\hline Occurrence of dispute & 20 & $61 \%$ \\
\hline Different interest and opinion & 23 & $70 \%$ \\
\hline Low management competency & 7 & $21 \%$ \\
\hline Ineffective communication network & 6 & $18 \%$ \\
\hline
\end{tabular}

Table 3. Top 10 network risks - likelihood \& impact

\begin{tabular}{lcccccc}
\hline \multicolumn{1}{c}{ Top 10 network risks } & $\begin{array}{c}\text { Likelihood }^{*} \\
\text { (mean) }\end{array}$ & Rank & $\begin{array}{c}\text { Impact* } \\
\text { (mean) }\end{array}$ & Rank & $\begin{array}{c}\text { (Likelihood) X } \\
\text { (impact) }\end{array}$ & Rank \\
\hline Different cultural norms & 5.05 & 8 & 4.47 & 10 & 22.57 & 9 \\
\hline Different work practices & 5.05 & 8 & 4.50 & 9 & 22.73 & 8 \\
\hline $\begin{array}{l}\text { Lack of risk management } \\
\text { knowledge }\end{array}$ & 4.75 & 10 & 4.75 & 8 & 22.56 & 10 \\
\hline Inaccurate information delivery & 6.29 & 2 & 6.00 & 3 & 37.74 & 3 \\
\hline $\begin{array}{l}\text { Lack of coordination and } \\
\text { communication }\end{array}$ & 5.17 & 6 & 5.39 & 5 & 27.87 & 6 \\
\hline Lack of trust and commitment & 6.39 & 1 & 6.39 & 1 & 40.83 & 1 \\
\hline Extensive subcontracting & 5.68 & 4 & 5.27 & 6 & 29.93 & 5 \\
\hline Subcontractor's subcontracting & 5.16 & 7 & 5.21 & 7 & 26.88 & 7 \\
\hline Occurrence of dispute & 5.30 & 5 & 5.70 & 4 & 30.21 & 4 \\
\hline Different interest and opinion & 6.00 & 3 & 6.35 & 2 & 38.10 & 2 \\
\hline
\end{tabular}




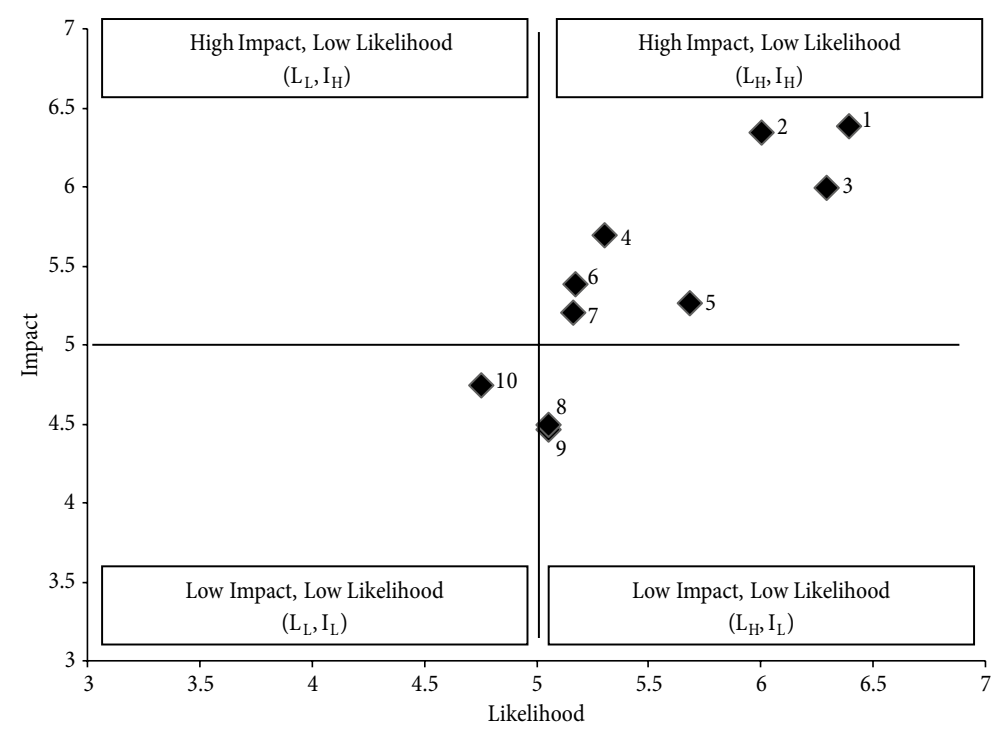

Fig. 1. Likelihood and impact of the top 10 critical network risks: 1 - Lack of trust \& commitment; 2 - Different interest \& opinion; 3 - Inaccurate information delivery; 4 - Occurrence of dispute; 5 - Extensive subcontracting; 6 - Lack of coordination \& communication; 7 - Subcontractor's subcontracting; 8 - Different work practices; 9 - Different cultural norms; 10 - Lack of risk management knowledge

Figure 1 provides an overview of the likelihood and impact of each risk and serves to illustrate those risks that must be prioritized first. The risks under the high impact and high likelihood area are: (1) lack of trust and commitment; (2) inaccurate information delivery; (3) different interests and opinions; (4) extensive subcontracting; (5) occurrence of a dispute; (6) lack of coordination and communication; and (7) subcontractor's subcontracting. In subsequent sections, only the first five risks are further discussed as the last two risks were placed close to the borderlines of " 5 " which indicate "Neutral" in terms of their likelihood and impact. The stakeholders who most contribute to the occurrence of the risks are also discussed together.

\subsubsection{Lack of trust and commitment}

As shown in Table 3, the lack of trust and commitment was found to have the highest rating among other risks in terms of likelihood of occurrence. The characteristics of the construction industry which include uniqueness, uncertainty, complexity, schedule pressure, and budget limitations can pose a negative impact on building trust among stakeholders (Cox, Thompson 1997). While trust is generally established over time after several interactions (Dervitsiotis 2003), most of the time, individuals involved in construction have had little or no prior experience with working with the other stakeholders. This increases the difficulty in building up trust at the beginning of the project and without trust, it is not possible for stakeholders in the network to develop commitment to others.

Similarly, the impact of lack of trust and commitment was the highest rated risk among the top 10 risks listed. According to Huemer (2004), trust is very important in the construc- 
tion industry for knowledge transfer and learning. Also, a successful business relationship typically depends on a trust-based relationship (Ferraro 2004). Without having trust and commitment, stakeholders in the network are less able to achieve cooperative behavior and adaptive organizational forms. A construction project requires a healthy relationship in order to function well.

As shown in Table 4, the stakeholder who most contributed to the lack of trust and commitment was found to be subcontractors, as reported by $54 \%$ of the respondents. One of the reasons may be because subcontractors are not directly employed by the client and are only responsible for a minor part of the construction work. This may cause subcontractors to be neglected in the project network. Also, their relationship with their employer, who is usually the contractor, is often a temporary one, and hence they do not recognize the need to develop trust and commitment with other project participants. Nonetheless, in order for the whole project to function well, all parties who are involved in the project should interact regularly and work in close collaboration with the essential parties.

\subsubsection{Inaccurate information delivery}

Inaccurate information delivery received a rather high rating for probability of occurrence, 6.29 , as shown in Table 3. Due to the availability of a great number of communication technologies, companies have adopted many disparate systems. This can lead to system incompatibility among stakeholders which can affect the quality and reliability of information transfer (Klemetti 2006).

Table 3 shows that the risk of inaccurate information delivery in the network was given a rating of 6 . Information is a major asset, and information dependency forms the backbone of the network. According to Howell and Ballard (1997), the success of the project largely depends on how well the information is managed within the network. With inaccurate information delivery, disputes might occur, more cost and time may be incurred, and eventually project performance may be affected greatly (Hwang, Lim 2013).

As seen in Table 4, the developer was listed as the stakeholder who contributes most to inaccurate information delivery. This can be explained by the fact that the developer tends to initiate construction projects, and basic project specifications arise from them. Although designers and the project manager are often the ones who assist the developer in determining the contents of the construction project, the developer is ultimately the final decisionmaker. Unfortunately, sometimes changes made by the developer are disseminated only to the parties working directly for the developer, such as the designers and contractors. Other stakeholders such as subcontractors might be neglected and not receive information that is of concern to them. In addition, when the root cause of information delivery problems is due to incompatible communication systems, there is a high possibility that the whole project will be affected.

\subsubsection{Different interests and opinion}

Different interests and opinions were ranked as third in both risk likelihood and impact, (Table 3) and the contractor was found to contribute most to the occurrence of this risk (Table 4). In the construction industry where stakeholders from multi-disciplinary fields 


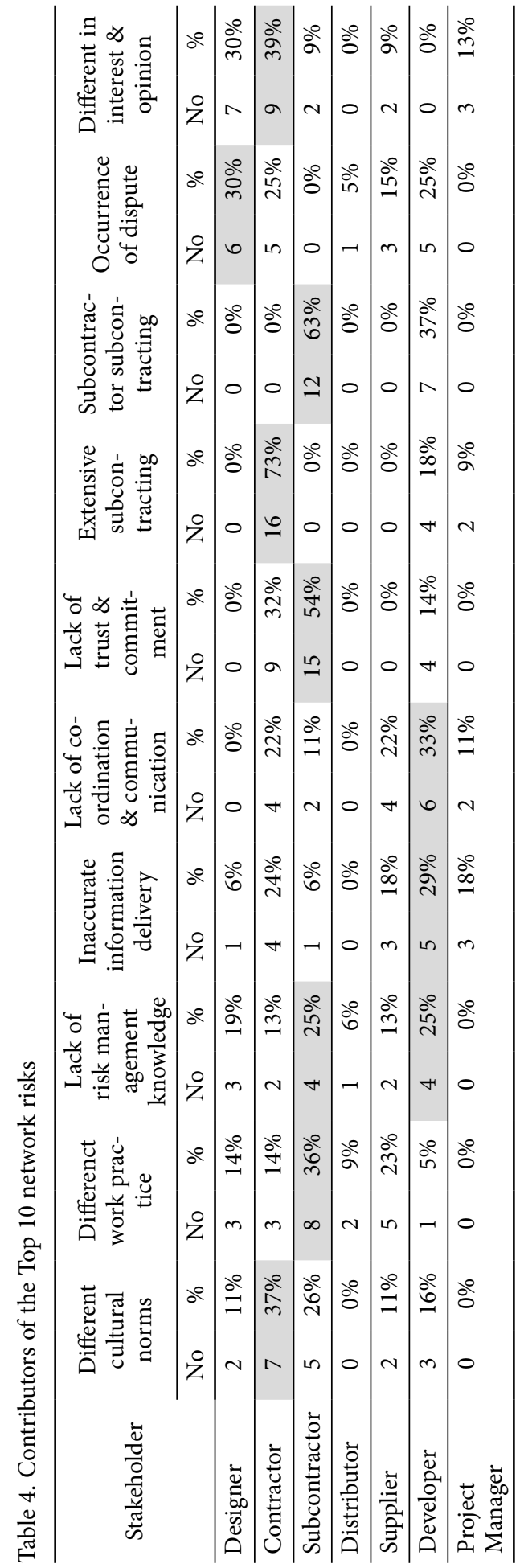


are involved, it is difficult to ensure that every interest, opinion and concern is taken into account. The situation is made worse if the collaborating party has an inflexible working behavior. Compromise and cooperation is the best way to ensure a win-win situation where both parties will gain. In order to improve stakeholder management and communication, the common goals, objectives and priorities of the project need to be systematically planned.

Stakeholders will be dissatisfied with the project outcome if their interest and concerns are not properly managed. Project progress might be disrupted when there is not enough endorsement to continue with the project. Failure to support the project can lead to overall project failure. This negative community reaction will likely affect future relationships among the stakeholders as well.

\subsubsection{Extensive subcontracting}

It is a common practice in the current construction industry to outsource a significant part of the construction work to subcontractors (Eccles 1981). However, as argued by Bova (1995), hiring subcontractors can create risk as the main contractor can lose control over subcontractor activities. The analysis results shown in Table 3 confirm Bova's view, indicating that the likelihood and impact of this risk is relatively high. While subcontracting may save time and promote a more efficient method for carrying out the work with specialized skills and labor, contractors need to regularly monitor their subcontractors' work and performance to ensure that everything is operating smoothly and to avoid variances. It is not surprising that the contractor contributes risk in this category as they are in-charge of the construction process and decide which parts of the work to let to subcontractors.

\subsubsection{Occurrences of a dispute}

Disputes ranked high in terms of their probability and impact, as shown in Table 3. This risk was found to be relatively closely connected with reports of differences in interests and opinions of stakeholders in the network. In other words, conflicting stakeholder concerns and objectives arise when project participants are not able to reach consensus (McIntosh, McCable 2003). Furthermore, disputes among stakeholders strain business relationships and are unhealthy for project performance. When conflict occurs, lost trust and commitment often follows quickly. Disputes decelerate the work progress and the lose-lose situation becomes more likely, which can further disrupt the schedule and budget.

Analysis results in Table 4 demonstrate that the designer, contractor and developer share responsibility for dispute risks, as they are the top three stakeholders. Over time, the expectations of the developer have become more stringent, and the current construction industry demands high quality along with reduced delivery schedule and budget. Due to the complex and challenging design that the designer has developed to meet the requirements of the developer, the contractor is naturally motivated to consider and plan for the building's constructability, given the amount of time and budget available. Accomplishing this goal requires constant attention and if no party is willing to compromise, disputes will occur. 


\section{Conclusions and recommendations}

This study aimed: (1) to explore the attitudes and understanding towards project network management in the Singapore construction environment; (2) to identify critical risks that affect the construction project network; and (3) to determine stakeholders who most contribute to these critical risks. To achieve the objectives, a survey questionnaire was designed and distributed to construction companies and the responses from a total of 33 contractors and subcontractors were analyzed.

The analysis results revealed that most of the respondents were unaware of network management and none of the participating companies implemented network management practices on their construction projects. Similarly, due to the relatively low level of understanding regarding the importance of network risk management, none of them performed any network risk management.

The top ten risks pertaining to the Singapore construction industry were also examined, analysing their likelihood of occurrence and impact. Also, the stakeholders who most contribute to these risks were identified so that managers can work to prevent network risks arising from mismanagement of these stakeholders.

The success of a construction project is greatly dependent on the stakeholders as they are the ones controlling the process and making important decisions. It is vital to build a good relationship and interaction among stakeholders to ensure smooth delivery during any stage of the process. Mismanagement of stakeholders in the network can pose threats to project success. Management needs to have sufficient knowledge to choose an appropriate, effective strategy for network management and network risk management. The findings from this study will help the industry to identify common network risks and to attain better understanding and attitudes towards network management, reducing potential risks that negatively affect project success. Greater awareness of the importance of stakeholder management among practitioners in the industry is a necessary corollary.

Although the objectives of this study were achieved, there are some limitations to conclusions that may be drawn from the results. The results collated from the survey questionnaire might be biased since the sample group only included contractors and subcontractors. Another limitation encountered in this study is that the findings are confined to the company level only. As project delivery methods such as design-bid-build, design-build, and project/construction management at risk or for fee can be one of the factors that influence project network and related management approaches, information at the project level should be collected as well to deepen the understanding of the relationships among network management, network risks and risk management. Furthermore, as the analyses were limited by small samples, caution is warranted when the results are generalized.

For future studies, it is recommended that the study of relationships among more stakeholders, which include contractors and subcontractors as well as owners, designers, consultants, etc. should extend beyond local project participants. As the construction industry commonly collaborates with stakeholders from other countries and employs foreign talent, it is important to study network risks that might occur when cooperating with construction firms from overseas. Also, the development of a severity index should be considered 
to capture a more holistic picture on the relationship between the likelihood and impact of a particular network risk. This would allow the stakeholders to understand the severity of each network risk and to facilitate them in implementing the appropriate measures to manage the risks and to utilize resources wisely.

\section{References}

Al-Bahar, J.; Crandall, K. 1990. Systematic risk management approach for construction projects, Journal of Construction Engineering and Management 116(3): 553-545. http://dx.doi.org/10.1061/(ASCE)0733-9364(1990)116:3(533)

Bennet, J.; Jayes, S. 1995. Trusting the team: the best practice guide to partnering in construction. Centre for Strategic Studies in Construction, The University of Reading.

Bourne, L.; Walker, D. H. T. 2005. Visualizing and mapping stakeholder influence, Management Decision 43(5): 649-660. http://dx.doi.org/10.1108/00251740510597680

Bova, A. J. 1995. Managing contractor risk, Risk Management 42(1): 45-51.

Chapman, C. B.; Ward, S. C. 2003. Project risk management: process, techniques and insights. $2^{\text {nd }}$ ed. Chichester, UK: John Wiley.

Chen, P.; Partington, D.; Maoshan, Q. 2009. Cross-cultural understanding of construction project managers' conceptions of their work, Journal of Construction Engineering and Management 135(6): 477-487. http://dx.doi.org/10.1061/(ASCE)CO.1943-7862.0000009

Chinowsky, P. S.; Diekmann, J. O’Brien, J. 2010. Project organizations as social networks, Journal of Construction Engineering and Management 136(4): 452-458. http://dx.doi.org/10.1061/(ASCE)CO.1943-7862.0000161

Cleland, D. I. 1999. Project management strategic design and implementation. Singapore: McGraw-Hill.

Construction Forum. 1995. Trusting the team: the best practice guide to partnering in construction. Centre for Strategic Studies in Construction, The University of Reading.

Cox, A.; Thompson, I. 1997. Fit for purpose contractual relations: determining a theoretical framework for construction projects, European Journal of Purchasing and Supply Management 3(3): 127-135. http://dx.doi.org/10.1016/S0969-7012(97)00005-1

Dervitsiotis, K. N. 2003. Beyond stakeholder satisfaction: aiming for a new frontier of sustainable stakeholder trust, Total Quality Management 14(5): 511-524.

http://dx.doi.org/10.1080/1478336032000053555

Di Marco, M. K.; Taylor, J. E.; Alin, P. 2010. Emergence and role of cultural boundary spanners in global engineering Project networks, Journal of Management in Engineering 26(3): 123-132. http://dx.doi.org/10.1061/(ASCE)ME.1943-5479.0000019

Eccles, R. 1981. The quasifirm in the construction industry, Journal of Economic Behavior and Organization 2(4): 335-357. http://dx.doi.org/10.1016/0167-2681(81)90013-5

English, J. 2002. The communication problems experienced by workforce on-site, and their possible solutions, Journal of Construction Research 3(2): 311-321.

http://dx.doi.org/10.1142/S1609945102000163

Ferraro, J. 2004. A question of trust, PM Network 18(12): 50-55.

Flanagan, R.; Norman, G. 1993. Risk management and construction. Victoria, Australia: Blackwell Science Pty Ltd.

Girmscheid, G.; Brockmann, C. 2010. Inter- and intra-organizational trust in international construction joint ventures, Journal of Construction Engineering and Management 136(3): 353-360.

http://dx.doi.org/10.1061/(ASCE)CO.1943-7862.0000142 
Horii, T.; Jin, Y.; Levitt, R. 2005. Modeling and analyzing cultural influences on project team performance, Computational \& Mathematical Organization Theory 10(4): 305-321. http://dx.doi.org/10.1007/s10588-005-6283-1

Howell, G.; Ballard, G. 1997. Factors affecting project success in the piping function, in L. Alarcon (Ed.). Lean construction. Rotterdam, The Netherlands: AA Balkema. http://dx.doi.org/10.4324/9780203345825_Factors_affecting_project_success_in_the

Huemer, L. 2004. Activating trust: the redefinition of roles and relationships in an international construction project, Journal of International Marketing Review 21(2): 187-201. http://dx.doi.org/10.1108/02651330410531394

Hwang, B. G.; Lim, E. S. 2013. Critical success factors for key players and objectives: case study of Singapore, Journal of Construction Engineering and Management 139(2): 204-215. http://dx.doi.org/10.1061/(ASCE)CO.1943-7862.0000597

Hwang, B. G.; Low, L. K. 2012. Construction project change management in Singapore: status, importance and impact, International Journal of Project Management 30(7): 817-826. http://dx.doi.org/10.1016/j.ijproman.2011.11.001

Hwang, B. G.; Zhao, X.; Toh, L. P. 2014. Risk management in small construction projects in Singapore: status, barriers and impact, International Journal of Project Management 32(1): 116-124. http://dx.doi.org/10.1016/j.ijproman.2013.01.007

Kazi, A. S.; Aouad, G.; Baldwin, A. 2009. Futuristic construction communication infrastructures: secure and safe with no wires, Journal of Information Technology in Construction 14(Special Issue): 526-539.

Klemetti, A. 2006. Risk management in construction project networks. Helsinki University of Technology, Monikko Oy, Finland.

Levina, N.; Vaast, E. 2008. Innovating or doing as told? Status Differences and overlapping boundaries in offshore collaboration, Management of Information Systems Quarterly 32(2): 307-332. http://dx.doi.org/10.2139/ssrn.1136880

Love, P. E. D.; Li, H.; Mandal, P. 1999. Rework: a symptom of a dysfunctional supply-chain, European Journal of Purchasing and Supply Management 5(1): 1-11. http://dx.doi.org/10.1016/S0969-7012(98)00017-3

Love, P. E. D. 2009. Communities and champions of practice: catalysts for learning and knowing, Journal of Construction Innovation 9(4): 365-371. http://dx.doi.org/10.1108/14714170910995912

Lowe, D.; Leiringer, R. 2006. Commercial management of projects: defining the discipline. Blackwell Publishing Ltd. http://dx.doi.org/10.1002/9780470759509

McIntosh, K.; McCable, B. 2003. Risk and benefits associated with international construction-consulting joint ventures in the English-speaking Caribbean, Canadian Journal of Civil Engineering 30(4): 1143-1152. http://dx.doi.org/10.1139/103-063

McManus, J. 2002. The influence of stakeholder values on project management, Management Services 46(6): 8-14.

Mitchell, R. K.; Bradley, R. A.; Wood, D. J. 1997. Toward a theory of stakeholder identification and salience: defining the principle of who and what really counts, Academy of Management Review 22(4): 853-885.

Nayak, N.; Taylor, J. 2009. Offshore outsourcing in global design network, Journal of Management in Engineering 25(4): 177-184. http://dx.doi.org/10.1061/(ASCE)0742-597X(2009)25:4(177)

Ozorhon, B.; Arditi, D.; Dikmen, I.; Birgonul, M. T. 2008. Implications of culture in performance of international construction joint ventures, Journal of Construction Engineering and Management 134(5): 361-370. http://dx.doi.org/10.1061/(ASCE)0733-9364(2008)134:5(361) 
Park, H.; Han, S. H.; Rojas, E. M.; Son, J.; Jung, W. 2011. Social network analysis of collaborative ventures for overseas construction projects, Journal of Construction Engineering and Management 137(5): 344-355. http://dx.doi.org/10.1061/(ASCE)CO.1943-7862.0000301

Pekericli, M. K.; Akinci, B.; Karaesmen, I. 2003. Modeling information dependencies in construction project network organizations, in Proceedings of $4^{\text {th }}$ Joint Symposium on Information Technology in Civil Engineering, 15-16 November 2003, Nashville, Tennessee, USA. http://dx.doi.org/10.1061/40704(2003)45

Schwegler, B. R.; Fischer, M. A.; O’Connell, M. J.; Hanninen, R.; Laitinen, J. 2001. Near-, medium-, and long-term benefits if information technology in construction, Working paper \#65, Center for Integrated Facility Engineering (CIFE), Stanford University, Stanford, CA.

Shirazi, B.; Langford, D.; Rowlinson, S. 1996. Organizational structures in the construction industry, Journal of Construction Management and Economics 14(3): 199-212. http://dx.doi.org/10.1080/014461996373467

Thomas, S. 2000. Impacts of Design/Information Technology on Project Outcome. GCR 99-978, National Institute of Standards and Technology (NIST) [online], [cited 15 February 2012]. Available from Internet: http://fire.nist.gov/bfrlpubs/build00/PDF/b00018.pdf

Ward, S. C.; Chapman, C. B. 2008. Stakeholders and uncertainty management in projects, Construction Management and Economics 26(6): 563-577. http://dx.doi.org/10.1080/01446190801998708

Wenger, E. 1998. Communities of practice: learning as a social system [online]. Systems Thinker [cited 15 February 2012]. Available from Internet: http://www.co-i-l.com/coil/knowledge-garden/cop/lss. shtml

Wong, K.; Unsal, H.; Taylor, J. E.; Levitt, R. E. 2010. Global dimension of robust project network design, Journal of Construction Engineering and Management 136(4): 442-451. http://dx.doi.org/10.1061/(ASCE)CO.1943-7862.0000143

Zhao, X.; Hwang, B. G.; Yu, S. 2013. Identifying the critical risks in underground rail international construction joint ventures: case study of Singapore, International Journal of Project Management 31(4): 554-566. http://dx.doi.org/10.1016/j.ijproman.2012.10.014

Bon-Gang HWANG (Dr) has been working as an Associate Professor in the Department of Building at National University of Singapore Since 2008. He has several years of experience in the construction industry, working with Samsung Engineering and Construction Company, Korea, and Construction Industry Institute, USA. In his doctoral research, he specialized in developing industry-specific performance indicators and measurement/analysis/reporting systems. He has over 80 publications including journal papers, conference papers, and books/reports in the areas listed. His current research interests are in the areas of sustainable construction project management, performance assessment and improvement, rework identification and analysis, and risk management.

Han Boey NG (Ms) graduated from the National University of Singapore in 2010 in Project and Facilities Management. She had been with Shimizu Corporation (Singapore) as an assistance quantity surveyor since 2001 . 